\title{
Geoprocessamento aplicado a análise geoambiental no Município De Vitória da Conquista-Bahia
}

\section{Geoprocessing applied to geo-environmental analysis in the Municipality Of Vitória da Conquista-Bahia}

\author{
Débora Paula de Andrade-Oliveira ${ }^{1}$ \\ Juliete Barros-Santos ${ }^{2}$ \\ Meirilane Rodrigues-Maia ${ }^{3}$ \\ Edvaldo Oliveira ${ }^{4}$ \\ Espedito Maia-Lima ${ }^{5}$ \\ Universidade Estadual do Sudoeste da Bahia, Brasil
}

http://dx.doi.org/10.15359/rgac.60-1.12

\begin{abstract}
RESUMO
O objetivo da pesquisa foi analisar as características geoambientais do município de Vitória da Conquista por intermédio do geoprocessamento, especialmente com o emprego do sensoriamento remoto e do SIG, com o propósito de apresentar possíveis subsídios ao planejamento ambiental para o município. No plano metodológico, realizou-se, uma discussão teórica e, paralelamente, a

1 Mestranda do Programa de Pós Graduação em Geografia da Universidade Estadual do Sudoeste da Bahia (PPGEO/UESB) Bolsista UESB. E-mail: deborapaulageografia@gmail.com

2 Graduanda do Curso de Geografia da Universidade Estadual do Sudoeste da Bahia (UESB) E-mail: julietebs@hotmail.com

3 Professora Doutora do Programa de Pós Graduação em Geografia da Universidade Estadual do Sudoeste da Bahia (PPGEO/UESB) E-mail: meire.rmaia@gmail.com

4 Professor Doutor do Programa de Pós Graduação em Geografia da Universidade Estadual do Sudoeste da Bahia (PPGEO/UESB) E-mail: edvaldocartografia@gmail.com

5 Professor Doutor do Programa de Pós Graduação em Geografia da Universidade Estadual do Sudoeste da Bahia (PPGEO/UESB) E-mail: espeditomaia@gmail.com
\end{abstract}

Fecha de recepción: 3 de julio de 2017

Fecha de aceptación: 8 de setiembre de 2017 
Débora Paula de Andrade-Oliveira, Juliete Barros-Santos, Meirilane Rodrigues-Maia, Edvaldo Oliveira, Espedito Maia-Lima. Geoprocessing applied to geo-environmental analysis in the Municipality Of Vitória da Conquista-Bahia

concepção e elaboração do projeto cartográfico e as análises empíricas. Os dados geográficos utilizados foram as bases vetoriais em formato shapefile e os dados rasters, com imagens do satélite Landsat 8 e do radar SRTM, ambos inseridos e processados no software livre de Sistema de Informações Geográficas QGIS, o sistema de referência de coordenadas adotado foi o SIRGAS 2000 UTM 24S. Os ambientes apresentam potencialidades e fragilidades específicas, que precisam ser consideradas no processo de uso e ocupação do solo, o que requer um planejamento municipal mais efetivo e coeso com a realidade local.

Palavras-chave: Análise Geoambiental. Geotecnologia. Planejamento Municipal.

\begin{abstract}
The purpose of this study was to analyze the geoenvironmental characteristics in the city of Vitória da Conquista through geoprocessing, especially with the use of remote sensing and SIG, in order to present potential subsidies to environmental planning for the municipality. At the methodological level, we performed a theoretical discussion and, in parallel, the design and preparation of the project chartplotter and the empirical analysis. The geographical data used was the basis vector shapefile format and the data rasters, with images of the Landsat 8 satellite and the SRTM radar, both entered and processed in the free software of Geographic Information System QGIS, and the coordinate reference system used was the SIRGAS 2000 UTM 24S. The environments have potential and specific weaknesses that need to be considered in the process of land use and occupation, which requires a city planning that is more effective and consistent with local reality.
\end{abstract}

Keywords: Geoambiental analysis. Geotechnology. City Planning.

\title{
Introdução
}

Os notáveis avanços no Geoprocessamento têm possibilitado sua maior aplicação em diversos segmentos da sociedade, especialmente, nas questões de natureza territorial como o planejamento territorial em suas diversas escalas e dimensões. Isso porque as técnicas que envolvem o geoprocessamento permitem uma análise integrada e minuciosa das características do território, constituindo-se, então, num conhecimento estratégico, sobretudo para os gestores municipais, no processo de decisão espacial. Sobre essa discussão, Veiga (2001) destaca a que “[...] A construção de uma base digital eficiente fornece informações relevantes ao processo de gestão do território, pois, otimiza o monitoramento do ambiente e permite adoção de políticas públicas coerentes, podendo evitar com isso, problemas de ocupação territorial desordenada" (Veiga, 2001, p.1). Desse modo, destaca ainda a relevância do geoprocessamento para o planejamento territorial.

No entanto, as ações do planejamento em escala municipal perderam importância nos últimos decênios, quer pela postura dos gestores municipais na busca de uma gestão de curto prazo, quer pela ausência de uma 
cultura que envolve a formação de um staff e absorção de profissionais especializados, principalmente, nos pequenos e médios municípios. Isso se dá apesar dos avanços das Geotecnologias, com os softwares livre (open source) de Sistemas de Informações Geográficas (SIG) e, sobretudo, a disponibilidade de bases cartográficas e de produtos do Sensoriamento Remoto (SR), de baixo custo ou mesmo sem ônus para os municípios.

Embora os avanços da Constituição Federal de 1988 tenham dado autonomia aos municípios, reconhecendo-os como ente federado e da legislação pertinente aos mesmos, como a Lei Orgânica e o Estatuto das Cidades (Lei 10. 257/02), além de programas para o planejamento ambiental como Agenda 21 entre outras, observa-se que estes, no geral, não reverteram para uma melhor eficiência e eficácia no planejamento municipal, principalmente, no âmbito ambiental.

No caso do planejamento ambiental, muitos têm aplicado apenas no contexto da elaboração do Plano Diretor, quase sempre para atender às demandas da legislação, tornando-se muitas vezes um instrumento apenas burocrático e distante da realidade. Além disso, os planos diretores dispõem, na maioria das vezes de mapeamentos compilados, mesmo diante da oferta de softwares livres, bases cartográficas vetoriais, imagens de satélite e de radar para a elaboração dos mapeamentos, que poderiam, caso elaborados com o critério científico e rigor metodológico, dar suporte ao planejamento e ao processo de tomada de decisão, dado o seu caráter estratégico. Convém mencionar, ainda, que nos estudos aplicados ao planejamento que envolve, principalmente, a morfologia urbana, os aspectos geoambientais, como a geologia, a pedologia e a geomorfologia pouco têm sido considerados nos planejamentos.

Diante desse quadro, o objetivo da pesquisa consiste em analisar as características geoambientais do município de Vitória da Conquista por meio da aplicações do geoprocessamento, envolvendo o sensoriamento remoto e o SIG, tendo em vista apresentar subsídios ao planejamento ambiental do município.

No plano metodológico, foi realizada uma discussão teórica, articulada ao projeto cartográfico e os trabalhos realizados em campo. Apresentam-se, assim, os mapeamentos das variáveis geomorfométricas e a carta de uso do solo, além das análises empíricas pertinentes a área de estudo. 
Débora Paula de Andrade-Oliveira, Juliete Barros-Santos, Meirilane Rodrigues-Maia, Edvaldo Oliveira, Espedito Maia-Lima. Geoprocessing applied to geo-environmental analysis in the Municipality Of Vitória da Conquista-Bahia

Assim, espera-se que os resultados apresentados possam dar suporte a um planejamento municipal efetivo que, alicerçado no conhecimento científico, se torne mais coeso com a realidade local.

\section{Marco teórico conceitual}

O que se discute no âmbito do planejamento ambiental com repercussões no município, deve remeter não somente ao traçado das vias e as morfologias, mas principalmente, ao uso da terra e sua dimensão social, cuja correlação tem sido pouco apontada nos mais diversos trabalhos. Correlacionar o planejamento municipal no campo dos estudos do meio ambiente com a estrutura da natureza física, aqui entendida como os aspectos da formação geológica, geomorfológica a partir do modelado pelos fatores climáticos, pressupõe um entendimento do aporte teórico que permita viabilizar os resultados do mapeamento, indicando, de forma clara, como esse planejamento ocorre.

O Geoprocessamento constitui-se numa vertente da Ciência Geomática que engloba as técnicas relacionadas ao tratamento da informação espacial nas esferas da coleta, do armazenamento, do processamento e da análise, com vistas ao estudo integrado desses dados geográficos (Oliveira, 2015). De modo mais amplo, convencionou-se denominar essas técnicas de Geotecnologias. Nesse contexto, Silva (2000) defende que as técnicas de Geoprocessamento, sobretudo, os Sistemas de Informações Geográficas, constituem-se como um viés muito profícuo para as análises espaciais na contemporaneidade.

Desse modo, compreende-se que o emprego de técnicas do geoprocessamento permite uma análise mais acurada desses fatores, que numa perspectiva sistêmica de interpretação torna possível uma maior aproximação com a dinâmica territorial que os rege. Assim, o geoprocessamento é definido, segundo Câmara (2001), pela utilização de técnicas matemáticas e computacionais com a finalidade de tratar informações geográficas.

As tecnologias livres em Geoprocessamento podem ser consideradas um divisor de águas no setor. Os softwares livres potencializaram o uso dessas tecnologias em diversos segmentos, uma vez que, ao contrário dos softwares comercias, não prescindem de aquisição da licença para a utilização e distribuição. Nesse sentido, Pinho (2011) relata as principais vantagens do emprego dos softwares livres: 
Débora Paula de Andrade-Oliveira, Juliete Barros-Santos, Meirilane Rodrigues-Maia, Edvaldo Oliveira, Espedito Maia-Lima. Geoprocessamento aplicado a análise geoambiental no Município De Vitória da

- $\quad$ Sem restrições de instalação e atualização do software de licenciamento fechado.

- Sem limites de utilização, de número de usuários, número de instalações, etc.

- Permite qualquer tipo de uso: pessoal, estudante, comercial, empresarial o institucional.

- Variedade de aplicativos, desde os completos GIS Desktop, passando pelas base de dados, servidores Web-GIS e bibliotecas de processamento e edição de dados (Pinho, 2011, p.15).

Entre os principais softwares livre em Geotecnologia estão: QGIS, gvSIG, Kosmo Gis, (tecnologias de âmbito internacional) Terra View e Spring (tecnologias nacionais).

Com esse entendimento, considera-se que os recursos cartográficos configuram-se como uma ferramenta com muitas potencialidades para o planejamento em diversas escalas territoriais. Dentre as formas de mapeamento, nas últimas décadas, têm sido utilizado os Sistemas de Informações Geográficas, composto basicamente por dados alfanuméricos, selecionados e organizados em uma base de dados relacional e dados espaciais, com feições de geometria pontual, linear e zonal, passíveis de serem visualizadas e editadas para a elaboração do mapeamento digital.

De acordo com Cintrão e Cintrão (2000) todas as feições existentes no SIG devem relacionar-se a um espaço geográfico, sendo o princípio essencial, "[...] em função da natureza das informações que pretendemos obter da análise desses dados" (Cintrão \& Cintrão, 2000, p.6).

Câmara et al (1996) defendem que os dados geográficos representam fatos, objetos e fenômenos associados a uma localização sobre a superfície terrestre, num certo instante ou período de tempo. Esses dados apresentam metadados, que se caracterizam " [...] como dados sobre os dados, informações estruturadas e utilizadas para descrever um recurso ou parte dele. Metadados Geoespaciais (MG) representam uma classe particular de metadados que permite caracterizar informações geoespaciais" (Daltio et al. 2012, p.3). Os autores diferenciam ainda os dados geográficos nas estruturas vetorial e raster, ao apontar que: 
Débora Paula de Andrade-Oliveira, Juliete Barros-Santos, Meirilane Rodrigues-Maia, Edvaldo Oliveira, Espedito Maia-Lima. Geoprocessing applied to geo-environmental analysis in the Municipality Of Vitória da Conquista-Bahia

[...] dados matriciais (raster) utilizam um conjunto de pixels para representar entidades espaciais sob uma forma numérica, sendo comumente representados em arquivos nos formatos. geotiff,. tiff, jpg ou .bmp, entre outros. Os dados vetoriais identificam dados singularmente como pontos, linhas ou polígonos e podem ser representados em arquivos nos formatos shape file (SHP) ou keyhole markup language (KML), por exemplo (Daltio et al. 2012, p.8).

O SIG é estruturado a partir da integração desses dados que, por intermédio do processamento, torna possível a obtenção de múltiplas informações sobre o território em análise. Florenzano (2008) relata que as aplicações das Geotecnologias, como o sensoriamento remoto, permitem a obtenção de dados referentes à superfície da Terra, indispensáveis para representação cartográfica do relevo. Nesse contexto, Moraes define o Sensoriamento Remoto como:

[...] um conjunto de atividades que permite a obtenção de informações dos objetos que compõem a superfície terrestre sem a necessidade de contato direto com os mesmos [...] Essas atividades abrangem a detecção, aquisição e análise (interpretação e extração de informações) da energia eletromagnética emitida ou refletida pelos objetos terrestres e registradas por sensores remotos (Moraes, 2002, p.7).

Florenzano observa, ainda, que os sensores do tipo Radar (Radio Detection an Ranging) são os mais indicados para a obtenção dos dados referentes ao relevo terrestre, uma vez que a radiação de micro-ondas é capaz de penetrar o dossel vegetal (FLORENZANO, 2008). Dessa forma, a disponibilização dos dados do Radar Shuttle Radar Topographic Mission (SRTM) para o Brasil tem possibilitado um maior conhecimento topográfico do território. Nesse sentido, Crepani e Medeiros afirmam que

O Projeto SRTM representa a primeira experiência de interferometria a bordo de uma nave espacial. No período de 11 a 22 de fevereiro de 2000 a bordo do Space Shuttle Endeavour, numa altitude de vôo de $233 \mathrm{~km}$ e uma inclinação de $57^{\circ}$, um conjunto composto por duas antenas coletou 14 Terabytes de dados que permitiram a avaliação do perfil de altitude para criação de modelo digital tri-dimensional da Terra entre as latitudes $60^{\circ} \mathrm{N}$ e $58^{\circ} \mathrm{S}$ (Crepani \& Medeiros, 2004, p.13). 
Os dados SRTM foram disponibilizados para a América do Sul em 2003, com resolução espacial de 90 metros (3 arc-segundos) posteriormente refinados pela National Aeronautics and Space Administration (NASA) e disponibilizado em 2014, com 30 metros (1 arc-segundo) de resolução espacial. Esse procedimento revelou significativo avanço na qualidade desses dados o que possibilitou uma maior acurácia nos mapeamentos, sobretudo, na obtenção de Modelos Digitais de Elevação (MDE), especialmente em escalas de análise mais detalhadas. Sobre esse aspecto, Valeriano (2008) aborda as possibilidades interpretativas do MDE para a análise ambiental:

Embora os MDE sejam um insumo fundamental ao conhecimento do relevo, muito de sua utilização numérica recai sobre variáveis derivadas da altimetria, como a declividade, o exemplo mais imediato. No entanto, deve-se lembrar que uso direto da elevação como fator analítico tem grande importância para espacialização de dados de temperatura, bem como estudos que envolvem hidrologia superficial, inundações e processos envolvendo movimentos gravitacionais. Como base para interpretação qualitativa, os dados altimétricos são tradicionalmente aplicados a incontáveis fins (Valeriano, 2008, p.22).

No campo da pesquisa geomorfológica, Florenzano (2008) evidencia o relevo como principal objeto de estudo dessa ciência, tendo em vista suas especificidades e a sua interação com os grandes domínios da natureza. Sobre esse aspecto, destaca a Geomorfologia como a ciência que analisa as formas de relevo, bem como sua gênese, composição e os processos que nelas atuam. Assim, “[...] o relevo da superfície terrestre é o resultado da interação da litosfera, atmosfera, hidrosfera e biosfera, ou seja, dos processos de energia e matéria que se desenvolvem nessa interface, no tempo e no espaço" (Florenzano, 2008, p.11).

O modelado terrestre é produto da dinâmica geomorfológica em processos complexos e contínuos. Apesar da influência dos mecanismos antigos nas configurações dos sistemas ambientais, principalmente no substrato rochoso, a organização dos elementos de maior dinamismo tem idade relativamente recente. A premissa amplamente utilizada na Ciência Geomorfológica, de que a maior parte das formas de relevo tem uma idade que não vai além do Pleistoceno, sendo exígua a topografia anterior ao 
Débora Paula de Andrade-Oliveira, Juliete Barros-Santos, Meirilane Rodrigues-Maia, Edvaldo Oliveira, Espedito Maia-Lima. Geoprocessing applied to geo-environmental analysis in the Municipality Of Vitória da Conquista-Bahia

Terciário conforme Thornbury (1954), se aplica, também, as outras variáveis da dinâmica das paisagens, tais como solos, drenagem e vegetação.

A partir dessa compreensão, Florenzano (2008) discute, ainda, a relevância da análise do relevo e o entendimento de suas formas e processos para as atividades humanas, uma vez que estas podem se configurar tanto como potencialidades, quanto limitações para o uso do território. Destaca que "[...] Dependendo de suas características, o relevo favorece ou dificulta a ocupação de ambientes terrestres pelo homem. De um lado, pode ser um obstáculo ao uso da terra e dificultar, além de encarecer, a construção de grandes obras de engenharia" (Florenzano, 2008, p.11). Compreende-se que o relevo e a rede hidrográfica podem se tornar um suporte para o estabelecimento de limites políticos entre municípios, Estados e países, ressaltando o valor da paisagem para a exploração do turismo, como aporte estratégico para fins militares.

Na mesma direção, Guerra (2008), destaca que o relevo terrestre é o principal alvo de investigação da Geomorfologia pois examina as diversas tipologias do relevo, a gênese, estrutura, natureza das rochas, cronologia entre outros aspectos da análise geomorfológica. Nessa vertente, para a sua efetivação, Florenzano observa que os estudos geomorfométricos referem-se ao registro de aspectos quantitativos do relevo, como as variáveis relacionadas as altura absoluta e relativa, declividade, curvatura, orientação, densidade e frequência de suas formas (Florenzano, 2008).

No campo da representação dessas variáveis geomorfométricas, aspectos referentes à elaboração cartográfica apresentam princípios da semiologia gráfica especifica. Dessa forma, a hipsometria refere-se às medidas altimétricas do relevo. Para Guerra:

[...] a hipsometria é a representação altimétrica do relevo de uma região no mapa, pelo uso de cores convencionais. De acordo com as normas cartográficas, as cores verdes representam as áreas mais baixas, e as de tom marrom e avermelhado, as das grandes altitudes (Guerra, 2008, p. 340).

Guerra aborda, ainda, o conceito de declividade que trata das variações na inclinação do relevo em relação ao horizonte. Nesse caso, a partir da representação em curvas de nível infere-se que "[...] quanto maior for à inclinação tanto mais próximas se encontram as curvas de 
nível e inversamente elas serão tanto mais afastadas quanto mais suave for o declive [...]" (Guerra, 2008, p.183). Esse processo dá origem ao gradiente definido pela declividade de uma encosta ou de um rio e expressa em graus ou em percentagem.

Dessa forma, compreende-se que a declividade configura-se numa variável geomorfométrica de fundamental importância para o planejamento ambiental. Diante disso, Valeriano (2008) considera que em decorrência da relação entre a declividade com processos de transporte gravitacional de matéria, podem ocorrer eventos como escoamentos, erosões e deslizamentos.

No campo das geotecnologias, a articulação entre as aplicações do Geoprocessamento na representação das formas do relevo permite uma abordagem mais completa e integrada dos ambientes terrestres. Nessa perspectiva, Guerra (2008) argumenta que por intermédio do Geoprocessamento, a análise geomorfológica, “[...] apoiando-se nos Sistemas de Informações Geográficas, pode, de forma mais rápida e precisa, analisar e classificar as formas de relevo, bem como os processos geradores dessas formas, ou seja, das várias unidades territoriais[...]" (Guerra, 2008, p.321). Desse modo, tais unidades constituem-se em cenários ambientais, que podem ser classificados e analisados por meio do geoprocessamento.

\section{Aspectos metodológicos}

Os procedimentos metodológicos adotados para a realização da pesquisa foram compartimentados em cinco etapas distintas. A etapa inicial pautou-se na definição do recorte territorial de estudo, o município de Vitória da Conquista, localizado na região sudeste da Bahia (Figura 1). Em seguida, optou-se discussão do referencial teórico e paralelamente, na terceira etapa, primou-se pela aquisição dos dados, processamento e sistematização do SIG. Na quarta etapa foram produzidos os documentos cartográficos e na última etapa foram realizadas as análises empíricas. 
Débora Paula de Andrade-Oliveira, Juliete Barros-Santos, Meirilane Rodrigues-Maia, Edvaldo Oliveira, Espedito Maia-Lima. Geoprocessing applied to geo-environmental analysis in the Municipality Of Vitória da Conquista-Bahia

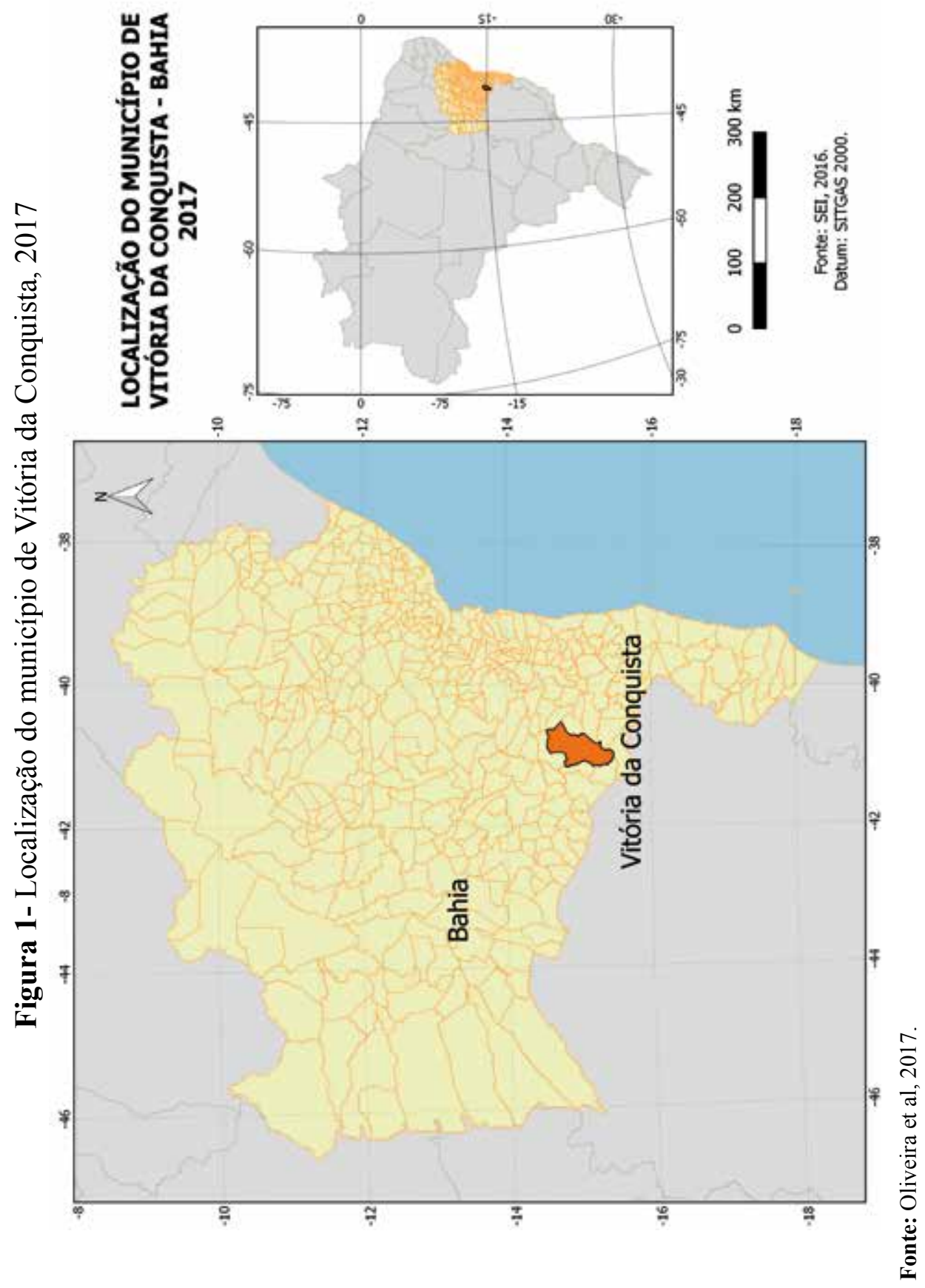

338 Revista Geográfica de América Central No 60 
$\mathrm{Na}$ estruturação do SIG, foram utilizados dados geográficos de arquitetura vetorial e raster, organizados na base de dados no formato de SIG. Em relação aos dados raster, foram inseridas quatro folhas do projeto SRTM, com 30 metros de resolução espacial. O moisacamento das folhas permitiu a cobertura da área de estudo, delimitada pelo polígono do município de Vitória da Conquista, em formato shapefile. Os dados foram inseridos no software QGIS, em que foi feita a composição do mosaico, para posterior reprojeção, com o sistema de referência de coordenadas SIRGAS 2000 UTM 24S e isolamento da área de estudo com o limite vetorial do município. Posteriormente, por intermédio dos algoritmos de geoprocessamento raster foram extraídas as cartas clinográfica, hipsométrica e a carta de sombreamento do relevo.

Ainda em relação aos dados raster, utilizou-se três cenas do satélite Landsat 8, para o imageamento da área de estudo. Esse satélite possui órbita circular, heliosíncrone, descendente, $98,2^{\circ}$ de Inclinação, com altitude de $705 \mathrm{~km}$. As cenas utilizadas correspondem as órbitas/pontos 217/70; 217/71 e 216/70 referentes ao mês de janeiro do ano de 2017.

As imagens do satélite Landsat 8 possuem originalmente 30 metros de resolução espacial, com possibilidade de conversão para 15 metros, a partir da fusão da banda 8 pancromática. A resolução temporal marca o tempo de revisitação do satélite é de 16 dias e a resolução espectral consiste em 11 bandas espectrais além de trazer a resolução radiométrica de 16 bits, com possível conversão para 8 bits. As cenas foram obtidas junto ao serviço geológico norte americano (USGS) e processadas no software QGIS.

O tratamento das cenas utilizadas foram processadas de acordo com os parâmetros do Processamento Digital de Imagens (PDI), envolvendo a composição RGB pseudo-cor com a banda 6 no canal Red, banda 5 no canal Green e banda 6 no canal Blue (R6G5B4). As cenas foram mosaicadas, reprojetadas para o Sistema de Referência Universal Transversa de Mercator e Datum SIRGAS 2000 24S.

No processo de elaboração da carta de uso do solo pautou-se na execução do processo de segmentação multiresolução e a classificação orientada a objeto, no software Ecognition Developer 8.9. A base vetorial oriunda da classificação foi exportada para o formato shapefile e processada no software QGIS, em que foi feita também uma auditoria cartográfica 
para avaliar a acurácia do mapeamento do uso do solo, considerando a verdade terrestre.

O projeto estruturado sob a arquitetura de um SIG permanece passível de alimentação para a posterior inserção de outras informações, com o intuito de gerar um banco de dados geográficos, com informações pertinentes às características geoambientais do município.

\section{Análises geoambientais do Município De Vitória da Conquista,} Bahia em suas compartimentações

O município de Vitória da Conquista abrange um território que pode ser compartimentado em três unidades geoambientais distintas: a) Planalto de Vitória da Conquista (PVC); b) Piemonte Oriental de Vitória da Conquista (POVC); c) Patamares do Rio de Contas (PMRC). Essas unidades geoambientais foram inseridas no SIG de acordo com a sua distribuição espacial no município. Desse modo, optou-se por sobrepor essa informação ao mapeamento das variáveis geomorfométricas para viabilizar sua melhor interpretação.

A Figura 2 apresenta a carta hipsométrica com a inserção da rede de drenagem do município contando com a rede hidrográfica, uma vez que o processo de entalhamento do relevo pelos corpos hídricos auxilia na compreensão da dinâmica morfogenética, que vem atuando sobre o território em análise. 
Débora Paula de Andrade-Oliveira, Juliete Barros-Santos, Meirilane Rodrigues-Maia, Edvaldo Oliveira, Espedito Maia-Lima. Geoprocessamento aplicado a análise geoambiental no Município De Vitória da

Conquista-Bahia

Figura 2 - Mapa Hipsométrico do município de Vitória da Conquista, 2017.

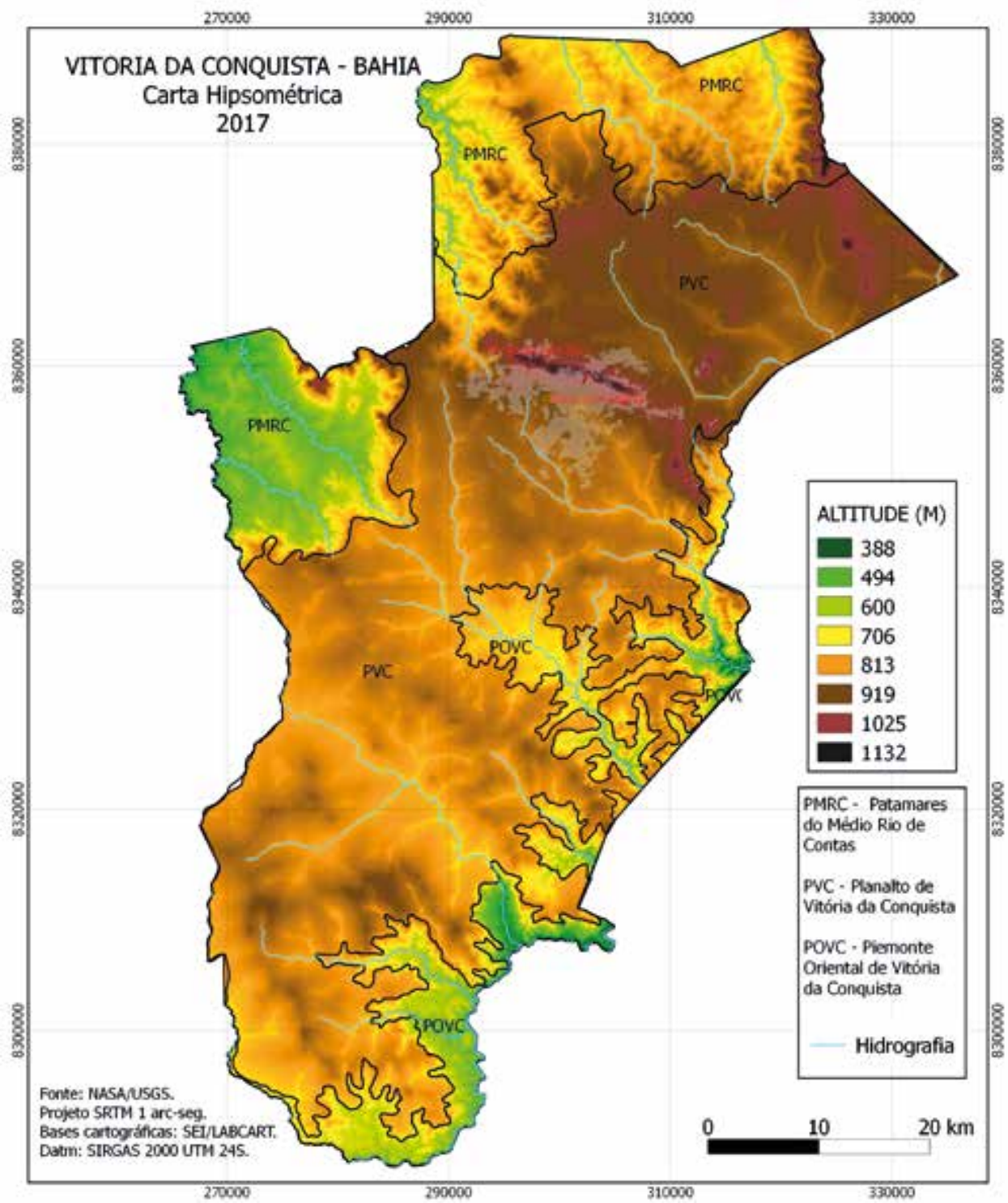

Fonte: OLIVEIRA et al, 2017. 
Débora Paula de Andrade-Oliveira, Juliete Barros-Santos, Meirilane Rodrigues-Maia, Edvaldo Oliveira, Espedito Maia-Lima. Geoprocessing applied to geo-environmental analysis in the Municipality Of Vitória da Conquista-Bahia

O município está localizado quase inteiramente sobre o Planalto de Vitória da Conquista, atravessando a região no sentido NE/SE, com uma altitude média de 800 metros, onde se destaca a Serra do Peri-Peri, com a crista residual quartzítica situada ao norte da cidade onde se registra a altitude mais elevada $(1132 \mathrm{~m})$ do município. A serra está localizada no perímetro urbano e, apesar de integrar uma Área de Proteção Ambiental (APA) atualmente encontra-se, em grande parte, ocupada pela população.

O Planalto de Vitória da Conquista é caracterizado pela ocorrência do relevo tabular, que compõe uma área geomorfologicamente estável, composta também por amplos planos inclinados, rampeados em sentidos diversos e moldados por vales de fundo chato e extremamente alargados (MAIA, 2005). Os limites entre o Planalto de Vitória da Conquista e as unidades vizinhas se dão quase sempre por vertentes abruptas. Na vertente oriental verifica-se a Serra (Escarpa) do Marçal e na vertente oeste, em direção à depressão sertaneja situa-se a Serra dos Pombos. No Planalto, predomina, em razão da forma tabular e baixa declividade, as pastagens, a eucaliptocultura e as culturas temporárias.

A unidade geoambiental denominada Piemonte Oriental de Vitória da Conquista está situada na direção NE/SE do município. Esse ambiente representa um nível intermediário entre as regiões do planalto e da depressão de Itapetinga, na vertente sudeste. A morfodinâmica local apresenta traços característicos de um processo de morfogênese muito ativo, com fortes movimentações na topografia, com altimetria oscilando entre 300 a $800 \mathrm{~m}$.

No que tange à utilização da terra, essa área é muito utilizada para a agricultura visto que, comparada a outras regiões do município, apresenta uma maior pluviometria. Tais condições se devem a disposição do relevo que se configura de forma perpendicular à orientação da maioria das massas de ar que se deslocam do litoral em direção ao interior do Estado, o que provoca as frequentes precipitações orográficas nessa área.

No tocante à degradação ambiental, a área abrangida pelo Piemonte Oriental corresponde a uma das unidades geoambientais mais degradadas pela influência das ações da sociedade. Devido às condições geoambientais, com chuvas orográficas abundantes e clima quente, a evolução morfogenética é predominantemente química, uma vez que ocorre a intensa decomposição das rochas e a ação incisiva da drenagem, conferindo à mesma uma topografia bastante irregular. Assim, o modelado de 
Débora Paula de Andrade-Oliveira, Juliete Barros-Santos, Meirilane Rodrigues-Maia, Edvaldo Oliveira, Espedito Maia-Lima. Geoprocessamento aplicado a análise geoambiental no Município De Vitória da

Conquista-Bahia

dissecação com altos gradientes de declividade são predominantes nessa unidade e pode ser observado na Figura 3 que apresenta a carta clinográfica do município.

Figura 3 - Carta clinográfica do município de Vitória da Conquista, 2017.

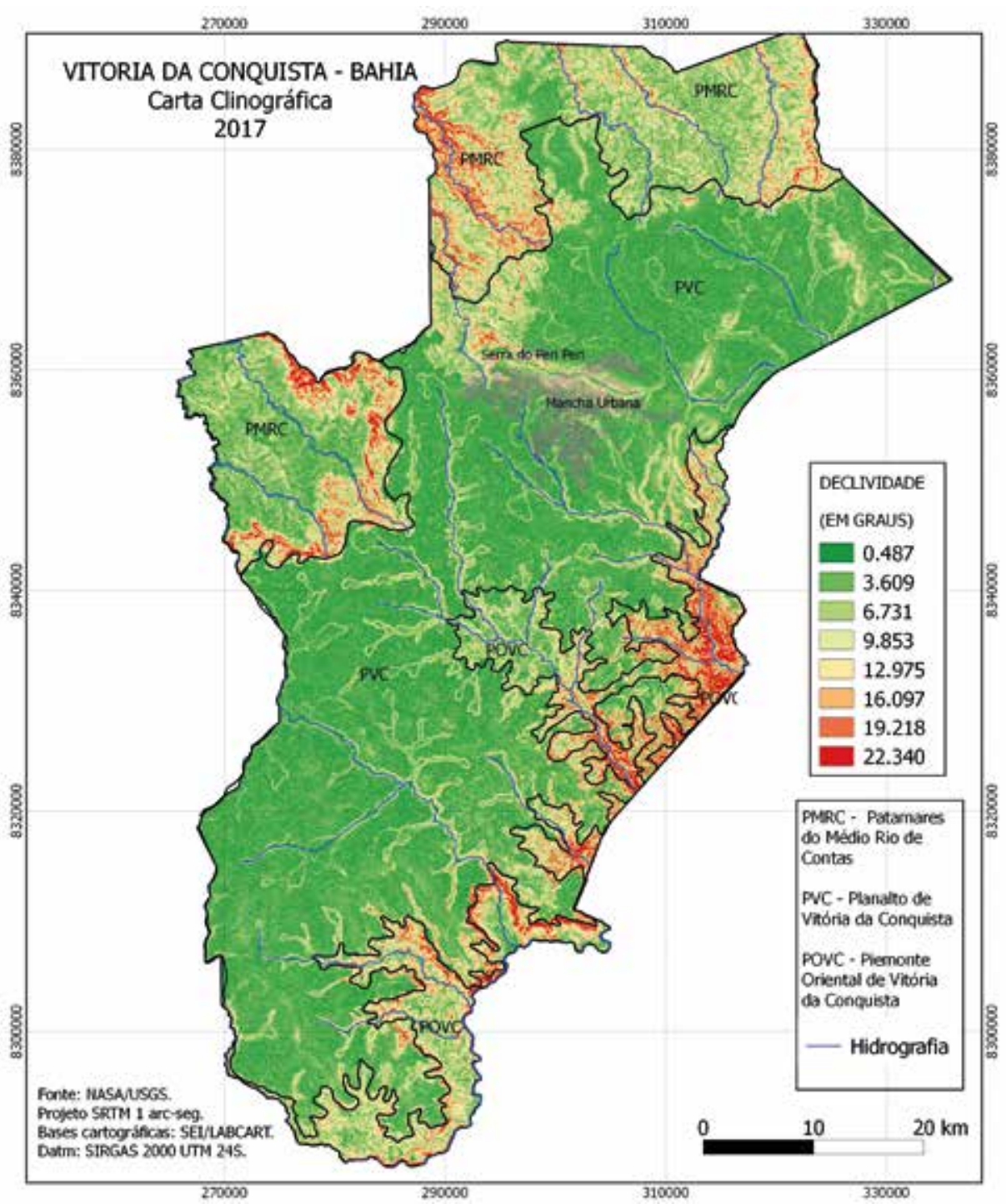

Fonte: OLIVEIRA et al, 2017. 
Os Patamares do Médio Rio de Contas corresponde a uma área de transição entre o Planalto de Vitória da Conquista e a Depressão Sertaneja, apresentando altitudes médias entre 388 e 900 metros, com alguns picos de maior elevação com $1.132 \mathrm{~m}$. Essa área é caracterizada pela intensa dissecação uniforme do relevo, apresentando incisão profunda da rede de drenagem e, ocorrência de dissecação, compondo sucessões de amplas lombadas e colinamentos rebaixados, onde predomina o escoamento superficial difuso e concentrado, que imprime suas marcas sob a vegetação da Caatinga, quase sempre rala, que recobre a unidade.

A rede de drenagem é regida pelos tributários da margem direita do Rio Gavião, onde o regime intermitente caracteriza a paisagem. Quanto ao uso do solo, predomina culturas temporárias com pastagens naturais típicas da caatinga com manchas de caatinga arbórea aberta e caatinga arbórea densa. A exploração agrícola tem provocado à devastação das paisagens naturais nesse recorte, com danos muitas vezes irreversíveis, uma vez que o ambiente da caatinga revela-se se de difícil resiliência quando degradado para além do seu limiar de recuperação natural. A carta de uso do solo (Figura 4) constitui-se num importante instrumento para a análise do território, por torna possível conhecer e quantificar seus usos. 
Débora Paula de Andrade-Oliveira, Juliete Barros-Santos, Meirilane Rodrigues-Maia, Edvaldo Oliveira, Espedito Maia-Lima. Geoprocessamento aplicado a análise geoambiental no Município De Vitória da

Conquista-Bahia

Figura 4 - Carta de uso do solo do município de Vitória da Conquista, 2017.

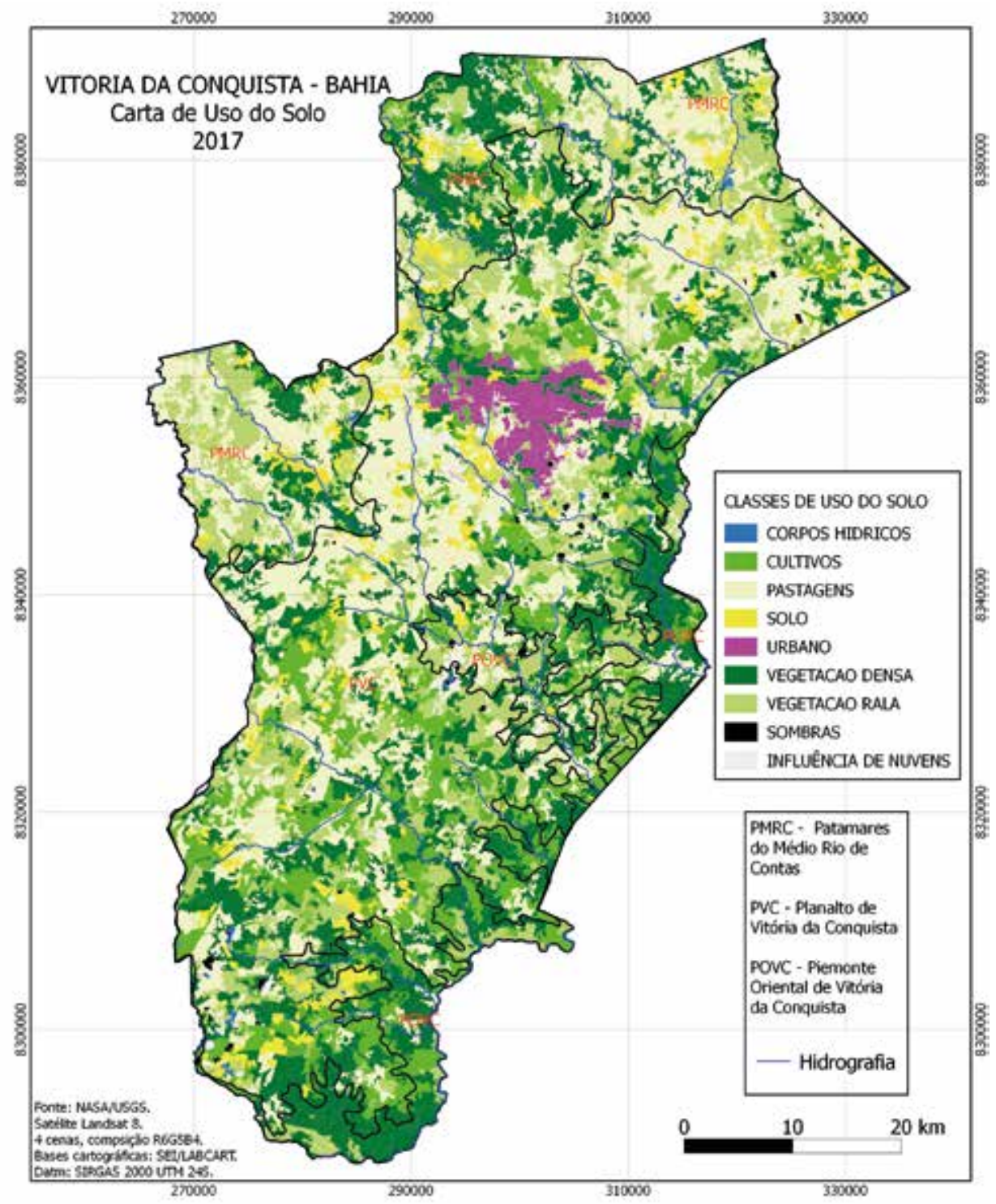

Fonte: OLIVEIRA et al, 2017. 
Débora Paula de Andrade-Oliveira, Juliete Barros-Santos, Meirilane Rodrigues-Maia, Edvaldo Oliveira, Espedito Maia-Lima. Geoprocessing applied to geo-environmental analysis in the Municipality Of Vitória da Conquista-Bahia

No caso da área leste, correspondente ao Piemonte Oriental, o alto índice de declividade constitui-se em um fator limitante de uso do solo. Contudo, é predominantemente utilizado com pastagens e diversos cultivos, especialmente, o plantio de café nas encostas, plantados em curvas de nível.

Na parte central, correspondente à área cimeira do Planalto, o uso da terra por pastagens e plantios temporários, com inserções de plantios de ciclo longo, como o eucalipto, mostram fragilidades quanto ao uso dá área interferindo na estabilidade do ambiente. Ressalta-se, também, a expansão da malha urbana da cidade, que avança para além do distrito sede, ocupando vastas áreas onde predominava florestas típicas como a subcaducifólia, além de interferir na qualidade da rede hidrográfica. Esse avanço marca a ineficiência do planejamento territorial urbano e por conseqüência, ambiental, que não leva em consideração os compartimentos geomorfológicos e as especificidades das unidades geoambientais.

No recorte dos Patamares do Médio Rio de Contas, nas áreas de caatinga, com predomínio da vegetação rala, apresenta um limiar de resiliência baixo, onde as atividades de ocupação do solo, embora apresente outra forma de uso em relação às outras duas unidades geoambientais, predomina a exploração mineral e a pastagem extensiva. Contudo, necessita de um planejamento, em função de sua fragilidade dada as características ambientais.

\section{Considerações finais}

A combinação dos agentes naturais endógenos, relativos à formação in situ, do ambiente, juntamente com as forças exógenas, marcadas pelas intempéries oriundas da dinâmica atmosférica aliadas às forças da ação da sociedade contribui para a configuração de diversas unidades de paisagens no município. Nesse sentido, considera-se que o fator geomorfológico assume grande relevância no processo de organização do espaço geográfico, uma vez que a diversidade das formas de relevo pode possibilitar ou limitar a utilização do ambiente pela sociedade, implicando, também, no planejamento ambiental.

A partir dessa compreensão, entende-se que os recursos cartográficos são indispensáveis ao planejamento e análise ambiental, uma vez que o mapeamento permite um maior conhecimento acerca do território, favorecendo, assim, a compreensão dos processos morfogenéticos, entre outros, que atuam na configuração do modelado. 
No que se refere ao planejamento ambiental do município, os fatores geoambientais e de uso da terra são fundamentais na análise, em razão das especificidades de cada ambiente, que podem se constituir como fatores limitantes ou potencializadores para os múltiplos usos e ocupação do solo, bem como pelas ações da sociedade e que se revelam na ausência de planejamento.

Nesse contexto, as preocupações remetem ao acelerado processo de exploração do ambiente, sem levar em conta às características das unidades geoambientais, resultando em problemas ambientais, que poderiam ser minimizados pelo conhecimento do território e que podem subsidiar o planejamento.

Nesse sentido, as aplicações do Geoprocessamento dão suporte a uma análise mais integrada da área do município, viabilizando o processo de tomada de decisão espacial e o ordenamento territorial.

O mapeamento permitiu conhecer melhor as características das unidades geoambientais do município, que se constitui como um dos instrumentos imprescindíveis à compreensão dos processos morfogenéticos que atuam na transformação das paisagens. Os procedimentos utilizados foram considerados eficazes para o desenvolvimento da pesquisa, permitindo desdobramentos futuros.

\section{Referências}

Câmara, G., Casanova, M. A., Hemerly, A. S., Magalhães, G. C. \& Medeiros. M. B. C. (1996). Anatomia de sistemas de informações geográficas. Campinas: Unicamp.

Cintrão, L. \& Cintrão, L. (2000). Geotecnologia Aplicada: planejamento Urbano GIS Brasil: Salvador.

Crepani, E. \& Medeiros, J. S. (2004). Imagens fotográficas derivadas de MNT do projeto SRTM para fotointerpretação na geologia, geomorfologia e pedologia. INPE: São José dos Campos.

Daltio, J. Spadotto, C. A. Santos, B. B. O. Fois, N. S. Martinho, P. R. R. Trajano, S. R. Holler, W. R. (2012). Infraestrutura Nacional de Dados Espaciais -Aspectos Computacionais. Comunicado Técnico: Campinas. Disponível em: $<\mathrm{http} / / /$ ainfo.cnptia.embrapa.br/digital/bitstream/item/84963/1/Comun-Tecnico-1-Gestao-Territorial-InfraestrutNac-Dados-Espac-ed01-2013.pdf> Acesso em dezembro de 2016. 
Empresa Brasileira de Pesquisa Agropecuária - Embrapa (1979). Serviço Nacional de Levantamento e Conservação de Solos. Rio de Janeiro, Súmula da $10^{\mathrm{a}}$ Reunião Técnica de Levantamento de Solos.

Florenzano, T. G. (Org) (2008). Geomorfologia: conceitos e tecnologias atuais. São Paulo: Oficina de textos.

Guerra, A. T. (2008). Dicionário Geológico-Geomorfológico. (6 ${ }^{\mathrm{a}}$ Ed). Rio de Janeiro: Bertrand Brasil.

IBGE. (2010). Censo Demográfico. Disponível em: <https://sidra.ibge. gov.br/Tabela/137\#resultado $>$. Acesso em: 20/003/2017

Lage, C. S. (1996). Evolução Geomorfológica do Curso do Vaza-Barris. Cadernos de Geociências da Universidade Federal da Bahia,5. Salvador: GEO, UFBA.

Maia, M. R. (2005). Zoneamento Geoambiental do Município de Vitória da Conquista - Ba: um Subsídio ao Planejamento.Dissertação (Mestrado em Geografia -Universidade Federal da Bahia, Salvador).

Moraes, E. C. de. (2002). Fundamentos de sensoriamento remoto. DSR/INPE. Oliveira, D. P.A. (2015). Cartografia urbana e memória da cidade: um olhar sobre as representações sociais dos bairros de Vitória da Conquista- Ba. (Monografia de graduação) UESB: Vitória da Conquista.

Satélite Landsat 8. Disponivel em $<$ https://landsat.usgs.gov/what-areband-designations-landsat-satellites $>$ Acesso em fevereiro de 2017.

Silva, J. X. da. (2000). Geomorfologia, Análise Ambiental e Geoprocessamento. Revista Brasileira de Geomorfologia, São Paulo, I, p.48-58.

Ross, J. L. S. (1996). Geomorfologia: ambiente e planejamento. São Paulo: Contexto.

Thornbury, W. (1954). Principles of geomorphology. New York: John Wiley \& Sons.

Valeriano, M. (2008). Topodata: guia para utilização de dados geomorfológicos locais. INPE: São José dos Campos. 